\title{
New Map Symbol System for Disaster Management
}

\author{
Silvia T. Marinova ${ }^{a}$ \\ ${ }^{a}$ Laboratory on Cartography, University of Architecture, Civil Engineering and Geodesy, Sofia, Bulgaria, \\ silveto_marinova@yahoo.com
}

\begin{abstract}
In the last 10 years Bulgaria was frequently affected by natural and man-made disasters that caused considerable losses. According to the Bulgarian Disaster Management Act (2006) disaster management should be planned at local, regional and national level. Disaster protection is based on plans that include maps such as hazard maps, maps for protection, maps for evacuation planning, etc. Decision-making and cooperation between two or more neighboring municipalities or regions in crisis situation are still rendered difficult because the maps included in the plans differ in scale, colors, map symbols and cartographic design. To improve decision-making process in case of emergency and to reduce the number of human loss and property damages disaster management plans at local and regional level should be supported by detailed thematic maps created in accordance with uniform contents, map symbol system and design. The paper proposes a new symbol system for disaster management that includes a four level hierarchical classification of objects and phenomena according to their type and origin. All objects and phenomena of this classification are divided into five categories: disasters; infrastructure; protection services and infrastructure for protection; affected people and affected infrastructure; operational sites and activities. The symbols of these categories are shown with different background colors and shapes so that they are identifiable. All the symbols have simple but associative design. The new symbol system is used in the design of a series of maps for disaster management at local and regional level.
\end{abstract}

Keywords: Disaster management, Disaster protection, Symbol system, Maps for disaster management

\section{Introduction}

Since 1990 both Europe and the whole world are increasingly affected by disasters, causing many casualties and material damage (EM-DAT, 2017). In the last 10 years Bulgarian territory was affected by various anthropogenic and natural disasters, such as: landslides, floods, earthquakes, snowstorms, windstorms and thunderstorms, drought, hailstorms, freeze, extreme temperatures, etc. (National Statistical Institute, 2017; Berberova, 2012; Frantsova, 2007).

Disaster management is a complex process including mitigation, preparedness, response, recovery and the actors in these activities need accurate geographical information presented on thematic maps that could support their specific activities. The success of the activities related to crisis management requires specialized geospatial information. Mapping for disaster protection is of the utmost importance for the development of programs for crisis management and prevention of serious consequences. Many projects funded by the European Union (EU) enable the development of cartography in areas such as early warning and disaster management (Konecny et al., 2008). A number of agencies and organizations related to disaster protection, such as the European Earth observation programme Copernicus, FEMA, EMA, UNISDR, develop disaster databases, geo-portals and cartographic product for crisis management. The ICA Commission on Cartography for Early Warning and Crisis Management supports the development of concepts and standards for compiling maps for early warning and disaster protection. The role of cartography in crisis management is to simplify and organize the necessary information. This makes the process of decision-making faster and more efficient and reduces fatalities and damages (Konecny \& Bandrova, 2006). The easy and rapid understanding of the information presented on specialized maps can be supported by uniform map contents, symbol system and design. Many countries around the world develop their own national standards for symbols, colors, fonts, design for the needs of topographic and other special maps (Bandrova, 2001), but in Bulgaria there is still not such a standard.

\section{Existing Symbol Systems for Disaster Management}

When a crisis situation occurs, the participants in crisis management require specialized maps to support their specific activities. One of the objectives of cartographers is to design effective representation of spatial information through graphic symbols (Akella, 2009). Designed symbols must be associative and should provide clear perception by users even without the use of a legend, especially in cases of emergency. Map symbols should have a clear and concise definition given in the legend on the map, but should also give users qualitative and quantitative information for the presented object or phenomenon (Konecny \& Bandrova, 2006). Many organizations have designed particular symbol systems for the needs of their activities (Bandrova et al., 2015).

One of the most popular symbol systems for crisis management is the set of 500 humanitarian symbols of the United Nations Office for the Coordination of 
Humanitarian Affairs (OCHA). The symbols are freely available at http://reliefweb.int/ and aim to help disaster responders to present information about crisis situations quickly and in a simple way (United Nations Office for the Coordination of Humanitarian Affairs, 2012). The symbols can be used in the production of humanitarian reports, maps, web-sites. All OCHA humanitarian icons are divided into 17 categories. The set of symbols covers both disasters and activities such as supply of water containers and equipment shelter, access to people in need and protection of civilians. The icons are associative and have simple structure that allows easy understanding. The Emergency Mapping Symbology (EMS) in Canada is developed under the auspices of GeoConnections, with participation from emergency management organizations across Canada. It is designed to be used by federal, provincial, regional and local organizations involved in the management of major events, disasters, and other incidents where emergency help and security are needed (GeoConnections, 2010). The symbology contains a set of symbols and a four level, hierarchical classification of the entities. The categories include incidents, infrastructures, operations, aggregates. Symbols in the same category have similar colors. The colors of incidents symbols are: dominantly shades of yellow/orange plus shades of blue (for water and weather), the colors of the symbols for infra-structures are dominantly shades of green, the colors of symbols for operations are dominantly shades of pink/red and the symbols of aggregates are colored in purple. In order symbols to be readable when printed in black and white, a version is also being provided with a white border adding a thin white buffer around the existing symbols.

The Association of Volunteer Emergency Response Teams developed a project called Disaster Response Map Symbols (DRMS) as an effort to compile a standard set of symbols aimed to support the creation of efficient maps for disaster management. The total number of the symbols is 285. The DRMS contains 5 families of symbols in a single font including vehicles, infrastructure, mobile/temporary services and teams, events, ships and some special symbols that do not fit to any of the previous groups (Association of Volunteer Emergency Response Teams, 2009).

Another popular symbol system is the symbology developed by federal, state, and local agencies in USA working together under the auspices of the Federal Geographic Data Committee (FGDC) Homeland Security Working Group. The symbol system includes symbols and their definitions for categories of Incidents, Natural Events, Operations, and Infrastructures. The structure of each category and a damage-operational status hierarchy were developed using color and frame shapes with line patterns (Homeland Security Working Group, 2017). The symbols are designed to be presented both in a color or a black and white form.

The advantages of these symbol systems and some more were taken in consideration in the design of a new symbol system for the needs of disaster management in Bulgaria.

\section{New Map Symbol System for Disaster Management}

Spatial information plays a key role in all activities related to crisis management / disaster protection. Participants in these activities require specialized maps that give them a clear idea of emergency, their localization, distribution, features and more. Therefore for quick and easy understanding of maps they should be created in accordance with uniform symbol system. In Bulgaria there is no accepted standard symbol system for early warning and disaster management. This often complicates the joint activities of two or more neighboring municipalities or regions in their efforts towards prevention, protection and disaster recovery.

A new map symbol system disaster management is developed. It is designed to be used in the production of maps for early warning and crisis management, to support the operational work of all participants in the Unified rescue system, regional and municipal administrations, as well as to help citizens read and understand specialized maps for emergency situations.

\subsection{Classification Structure}

The new symbol system contains a classification of objects and phenomena concerning disaster protection and a set of symbols. A 4-level hierarchical structure is used for the classification. At the highest level all objects and phenomena are divided into 5 categories:

- Disasters;

- Infrastructure;

- Protection Services and Safety Infrastructure;

- Affected People and Infrastructure;

- Operational Sites and Activities.

Each category is divided into classes, and they in turn are divided into subclasses, which consists of objects and phenomena.

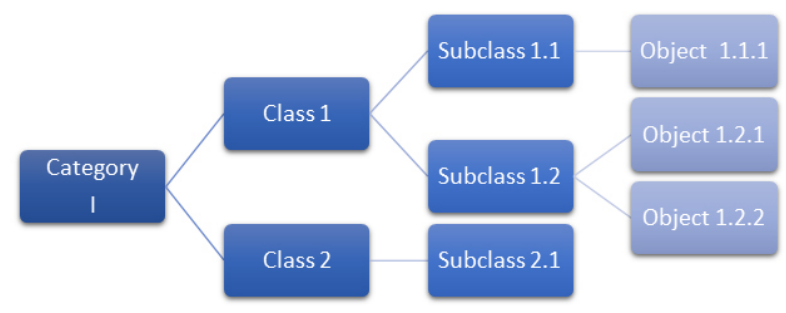

Fig. 1. Classification structure

\subsection{Design of Symbols}

The symbols consist of pictograms in white color and shapes with a particular background color. For each category a different shape is chosen as well as a different background color (Table 1). Different shapes and colors sup-port rapid association of the symbols to the appropriate categories.

Different shapes for all categories aim to avoid potential problems due to low light or black and white printing. The choice of the shapes for each category is consistent 
with the established practice in other countries such as USA, Portugal and others.

\begin{tabular}{|c|c|c|c|}
\hline Category & $\begin{array}{l}\text { Shape and } \\
\text { Color }\end{array}$ & $\begin{array}{l}\text { RGB } \\
\text { Color }\end{array}$ & $\begin{array}{l}\text { CMYK } \\
\text { Color }\end{array}$ \\
\hline Disasters & & $\begin{array}{l}255- \\
0-0\end{array}$ & $\begin{array}{c}0-100- \\
100-0\end{array}$ \\
\hline $\begin{array}{c}\text { Infrastructu } \\
\text { re }\end{array}$ & & $\begin{array}{r}90- \\
0-185\end{array}$ & $\begin{array}{c}80-90- \\
0-0\end{array}$ \\
\hline $\begin{array}{c}\text { Protection } \\
\text { Services and } \\
\text { Safety } \\
\text { Infrastructure }\end{array}$ & & $\begin{array}{c}0- \\
100- \\
255\end{array}$ & $\begin{array}{c}80-60- \\
0-0\end{array}$ \\
\hline $\begin{array}{c}\text { Affected } \\
\text { People and } \\
\text { Infrastructure }\end{array}$ & & $\begin{array}{r}255- \\
125-0\end{array}$ & $\begin{array}{l}0-65- \\
100-0\end{array}$ \\
\hline $\begin{array}{l}\text { Operational } \\
\text { Sites and } \\
\text { Activities }\end{array}$ & & $\begin{array}{c}35- \\
150-0\end{array}$ & $\begin{array}{c}80-15- \\
100-0\end{array}$ \\
\hline
\end{tabular}

Table 1. Basic geometric shapes and background colors of symbols of each category (Source: Marinova, 2014)

The presentation of objects and phenomena which are more important than others is achieved by increasing the size of their respective symbols $x$ 1.5. The total number of designed symbols is 115. All categories are distinguishable by their shape and color. The design of the pictograms is simple but not too simple as symbols should be associative and give information for concrete objects and phenomena. Similar elements in different symbols have similar thicknesses, lengths and the same general design.

Each category has an individual letter code (Table 2) and each symbol gets an alphanumeric code formed by Category code and serial number of the symbol in its category.

\begin{tabular}{|lc|}
\hline Category & Code \\
\hline Disasters & A \\
\hline Infrastructure & B \\
\hline $\begin{array}{c}\text { Protection Services and Safety } \\
\text { Infrastructure }\end{array}$ & C \\
\hline $\begin{array}{c}\text { Affected People } \\
\text { Infrastructure }\end{array}$ & and \\
\hline
\end{tabular}

\section{Operational Sites and Activities}

$\mathrm{E}$

Table 2. Category codes

Figure 2, 3, 4, 5, and 6 present a part of the symbol system including alphanumeric code, graphic symbol, a brief description.

$\begin{array}{lll}\text { A09 } & \text { Frost } \\ \text { A10 } \approx \text { Flood } \\ \text { A11 } \\ \text { A12 }\end{array}$

Fig. 2. Symbols of category A
B23

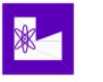
Nuclear Power Plant
B24
4 Power Plant
B25
4 Power Substation
B26

\section{Í Industrial Factory}

Fig. 3. Symbols of category B

Bor Clinic
Border Police Office
C05

Fig. 4. Symbols of category C

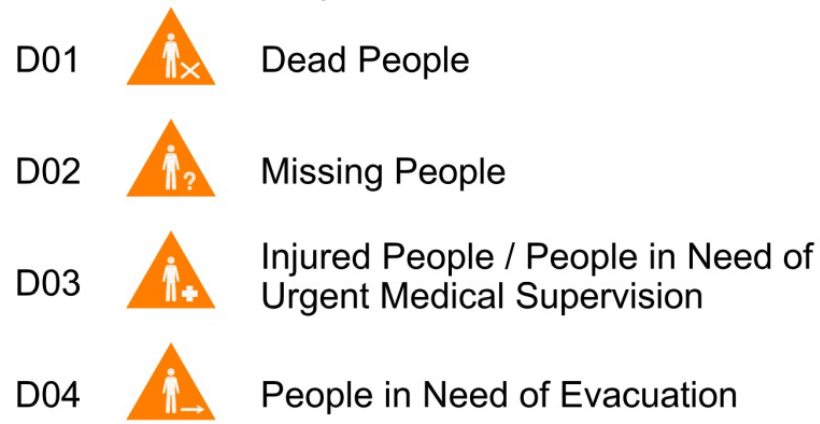

Fig. 5. Symbols of category D 


E06 Rescue Group
E07 Temporary Medical Center
E09

Fig. 6. Symbols of category E (Source: Marinova, 2014)

\subsection{Combined Map Symbols}

Presenting the status and condition of objects of Infrastructure and Protection Services and Safety Infrastructure in crisis situation is performed combining symbols from category B and C with symbols D05, D06, D07 category D. In this combination, the symbols of Category D have reduced sizes and are located in the upper right corner of the symbols of categories $\mathrm{B}$ and $\mathrm{C}$ (Fig. 7).

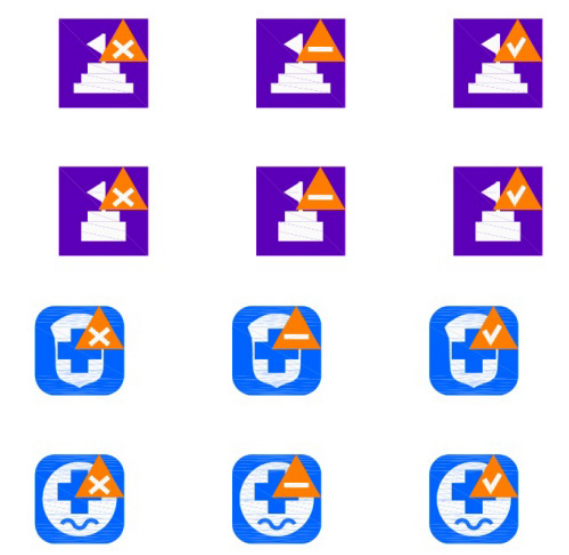

Fig. 7. Symbols presenting affected Infrastructure and Protection Services and Safety Infrastructure in crisis situation

The new symbol system has been applied in the experimental development of a series of maps designed to be included in the Plan for Disaster Protection of Troyan Municipality, and in the design of maps supporting training for action in an operational situation in Elin Pelin Municipality.

\section{Application of the Symbol System in Maps for Disaster Management}

The town of Troyan, Lovech region is situated in a mountainous area in North Bulgaria, $160 \mathrm{~km}$ northeast of Sofia. It is a municipal center of 21 settlements with a total area of 893 square kilometers and population of 32 400 inhabitants (according to the census in 2011). Based on the Disaster Management Act (2006) a Disaster Protection Plan of Troyan Municipality is developed, which is introduced in implementation in case of disaster by order of the mayor.

The main tasks of the Disaster Protection plan of Troyan Municipality (2008) are:
- analysis, assessment and prediction of disaster risks for the territory of the municipality of Troyan;

- defining measures for disaster prevention and measures for mitigation of effects of disasters;

- building up an early warning system and coordinating the disaster management activities;

- early warning;

- other.

Depending on the role of participants in these activities, they need specialized geographic information to support their concrete actions. Based on the analysis of possible disasters in the municipality and given mandatory according to Disaster Management Act parts is established advisability of making specialized plans for: earthquakes, floods, fires, industrial accidents, radiation accidents (Disaster Protection Plan of Troyan Municipality, 2008).

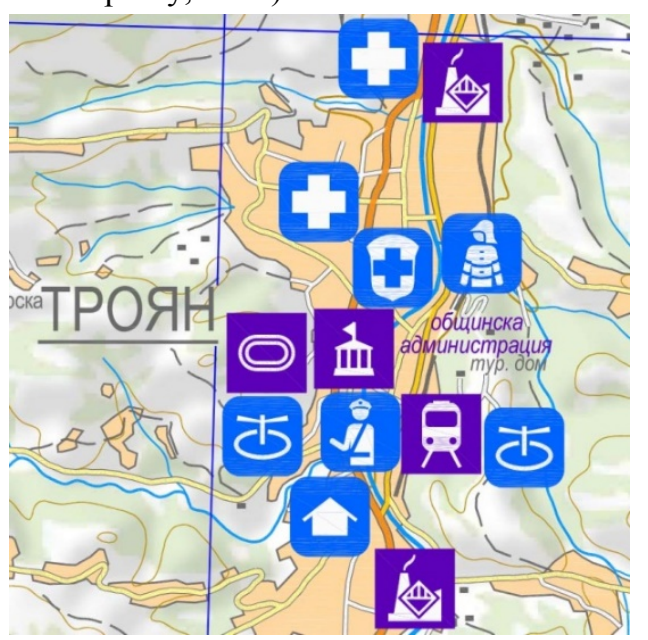

Fig. 8. Base maps of Troyan Municipality (fragment)

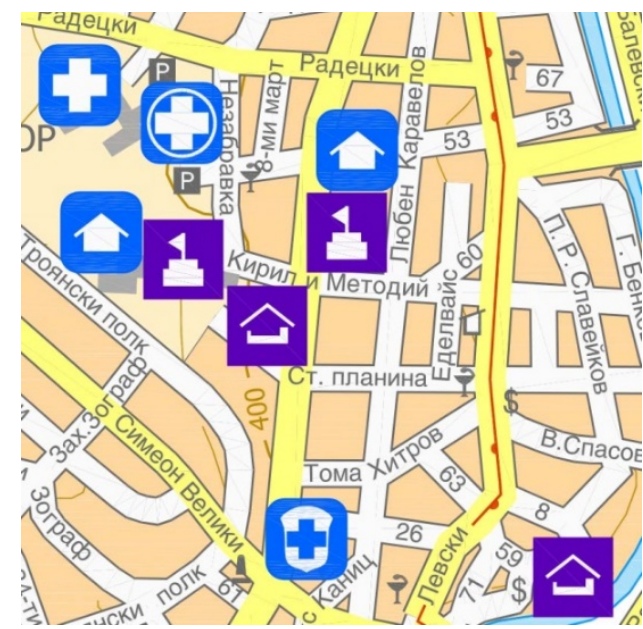

Fig. 9. Base maps of the town Troyan (fragment)

For the needs of the activities described in the Disaster Protection plan base maps of Troyan Municipality in scale 1:50 000 (Fig. 8) and the town of Troyan in scale 1:10 000 (Fig. 9) were created according to predefined ele-ments of map content using the new map symbols for disaster managements (Marinova, 2014, Marinova, 2014b;). The based maps were used for the creation of a 
series of maps for disaster management in case of earthquakes, floods, fires, industrial accidents, radiation accidents as a part of the Specialized plans for Disaster Protection in Troyan Municipality. All these maps, their contents and design are presented in details by Marinova (2014).

A map of Elin Pelin Municipality in scale 1:50 000 based on a scenario for evacuation operations planning was also created. The special content of the map is consistent with the information about the operational situation. It presents occurred disasters, affected people, affected infrastructure, safety routes for evacuation (Fig. 10). The map content and displayed information of the operational situation aim at supporting disaster managers, responsible authorities and individuals to make quick and effective decisions. The map allows the identification of affected areas in the municipality, gives significant contributions to the activities for population protection and mitigation, as well as planning evacuation operations.

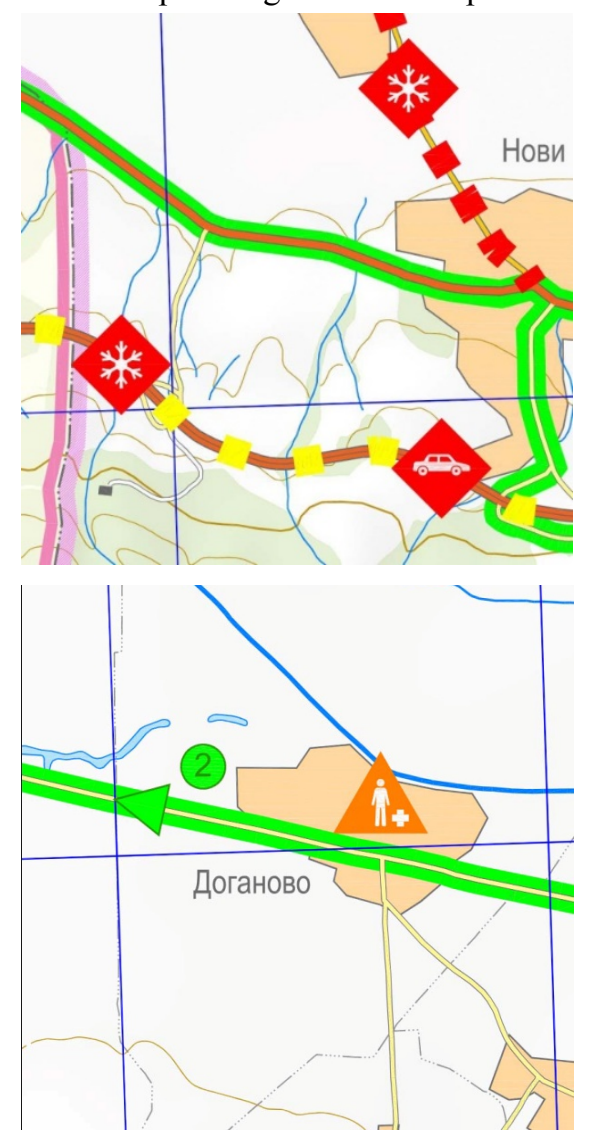

Fig. 10. Fragments of a map of Elin Pelin Municipality for evacuation operations planning

The new map symbols were also used in the creation of a map of Strandzha mountain for forest fires protection (Fig. 11). The map of over $13100 \mathrm{~km}^{2}$ forest area was designed in implementation of the cross-border project "Strandzha/Yildis the mountain is without fires" covering the area of the state border between the Republic of Bulgaria and the Republic of Turkey along $182 \mathrm{~km}$. Its thematic content represents the boundaries of the Bulgarian and the Turkish forestry enterprises, the classes of fire hazard of the forest areas within the scope of the project, the specialized services and the constructed firefighting infrastructure, the protected areas and the objects that attract a lot of visitors which increase the fire hazard in Strandzha.

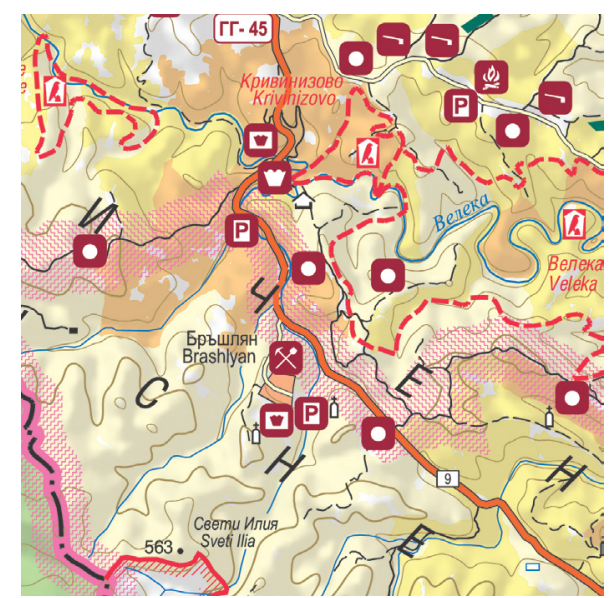

Fig. 11. Map of Strandzha/Yildis the mountain is without fires (fragment)

\section{Conclusions}

The main objective of this study is development of a new map symbol system supporting the creation of thematic cartographic products intended to be included into disaster management plans. The symbol system can be used for maps for early warning and crisis management, to support the operational work of all participants in the Unified rescue system, regional and municipal administrations, as well as to help citizens reading specialized maps for emergencies. The classification of objects / phenomena and the cartographic design of the symbols included in the new system aim to improve the whole process of crisis management and to facilitate the collaboration of local and regional authorities in efforts to mitigate shared disasters.

\section{References}

Akella, M.K. (2009). First Responders and Crisis Map Symbols: Clarifying Communication, Cartography and Geographic Information Science, Volume 36, Issue 1, 2009, Taylor\&Francis, Published online: 14 March 2013

Association of Volunteer Emergency Response Teams, (2009). Disaster Response Map Symbols, version 1.01 (Beta)

Bandrova. T. (2001). Designing of Symbol System for 3D City Maps, UACEG, Sofia

Bandrova, T., Kouteva M., Pashova L., Savova D., Marinova S. (2015). Conceptual Framework for Educational Disaster Centre "Save the Children Life". The International Archives of the Photogrammetry, Remote Sensing and Spatial Information Sciences, Volume XL-3/W3, 2015 ISPRS Geospatial Week 2015, 28, La Grande Motte, France. pp. 225-234. doi:10.5194/isprsarchives-XL-3-W3-225-2015

Berberova, R. (2012), Natural Disasters in Bulgaria, New Bulgarian University, Sofia, ISBN 978-954-535-699-5 
Disaster Management Act (2006), Council of Ministers of Republic of Bulgaria

Disaster Protection Plan of Troyan Municipality (2008), Adopted by Municipal Council of Troyan in 2008

Frantzova A. (2007) Hybrid Method for Complex Risk Analysis of Natural Disasters, Sofia

GeoConnections, Emergency Mapping Symbology, Version 1.0, (2010) http://emsymbology.org/, Accessed March 2014

Homeland Security Working Group, Symbology Reference, http://www.fgdc.gov/HSWG/index.html, Accessed 20 Feb 2017

EM-DAT, The International Disaster Database, Centre for Research on the Epidemiology of Disasters CRED,EM-DAT Database Advanced Search, http://www.emdat.be/advanced search/index.html, Accessed 27 Feb 2017

Konecny M., T. Bandrova, P. Kubicek, (2008). Similarities and Differences in Cartographic and Geoinformatics support of Early Warning and Disaster / Crises Management, Seminar with EU Cooperation on Early Warning and Disaster / Crises Management, Proceedings 2, 2nd International Conference on Cartography and GIS, Borovets, Bulgaria, 2008, ISBN: 978-954-724-038-4

Konecny M., T. Bandrova, (2006). Proposal for a Standard in Cartographic Visualisation of Natural Risks and Disasters. International Journal of Urban Sciences, Vol. 10, Issue 2,

Marinova S. (2014). Thematic Mapping and Visualization for Early Warning and Crisis Management, UACEG, Sofia

Marinova S. (2014b). Analysis of Content of Thematic Maps for Disaster Management at Local Level, 5th International Conference on Cartography and GIS, June, 15-20, 2014, Riviera, Bulgaria, USB Proceedings, Vol. 2, Bulgarian Cartographic Association, ISSN: 13140604

United Nations Office for the Coordination of Humanitarian Aaffairs (OCHA). (2012) World: Humanitarian and Country Icons 2012, http://reliefweb.int/report/world/world-humanitarianand-country-icons-2012, Accessed 23 Feb 2017 